\title{
Do subdesenvolvimento à interdependência: as duas pontas do nó
}

\section{Ligia Chiappini ${ }^{1}$}

\begin{abstract}
Resumo
Trata-se de retomar a reflexão sobre as relações entre o local e 0 global, a partir de posições explícita ou implicitamente defendidas em textos de Antonio Candido e de Paulo Emílio Salles Gomes, no sentido de superar a simples oposição centro-periferia, pelo reconhecimento da interdependência, sem mascarar o peso do subdesenvolvimento e a condição periférica de um País como o Brasil, e o que ela implica tanto na produção quanto na difusão das mercadorias, incluídas aí as letras e as artes.
\end{abstract}

Palavras-chave

Centro, periferia, local, global, crítica, literatura, cinema.

Recebido em 7 de abril de 2011

Aprovado em 6 de junho de 2011

I Profa. Dra. Titular de Brasilianistik (Literatura e Cultura Brasileiras), na Universidade Livre de Berlim. E-mail: lchiappini@gmail.com 


\title{
From underdevelopment to interdependency: two ends of a knot
}

\section{Ligia Chiappini}

\begin{abstract}
A return to reflection on the relationship between the local and the global as based on the positions explicitly or implicitly defended in the writings of Antonio Candido and Paulo Emílio Salles Gomes, with a view toward overcoming a simple "center-periphery" opposition through recognition of interdependency, albeit without glossing over the weight of underdevelopment and the peripheral condition of a country like Brazil and its significance in terms of production and the diffusion of marketable goods, the arts and literature included.
\end{abstract}

Keywords

Center, periphery, local, global, criticism, literature, cinema. 


$$
0
$$


aceitos como internacionais, ou globais, apresentando-se, de saída, como cidadãos do mundo, para fugir à pecha de periféricos, dependentes, subdesenvolvidos ou, até mesmo, emergentes. Os mexicanos declararam-se, ao final, nem mexicanos nem europeus, mas simplesmente escritores, ou, no máximo, interdependentes. O brasileiro definiu-se como um escritor que fala de e para muitos cantos do mundo. $\mathrm{O}$ argentino, da velha guarda, aparentemente tinha posição oposta, mas tampouco contribuiu para desatar o nó, pois atrapalhou mais ainda tudo com uma atitude démodé, quase patética, embora trazendo à tona algumas verdades que todos pareciam querer esquecer: entre outras, a existência de um muro, cada vez maior, entre pobres e ricos, e a fome que grassa num mundo de fartura. Essas verdades, porém, se aguavam pela performance por ele adotada e pela insistência em polemizar, em agredir, colocando-se de pé, quando todos estavam sentados, ou repetindo monotonamente esta frase: "Donde hay hambre no hay hombre".

Tal debate evidenciou algo a ser discutido na sequência: que entre o ressentimento apocalíptico de quem se reconhece na periferia (embora more no centro) e o idealismo compensatório de quem pensa estar integrado ao centro (embora more na periferia), porque assim se deveria pensar o mundo interdependente da atualidade, permanecemos com um vazio e o nó persiste.

Antonio Candido e Paulo Emílio podem ajudar, senão a desatar esse nó, pelo menos a entendê-lo melhor, o que é condição preliminar para desfazê-lo. Os textos de referência são aqui principalmente dois, cujos pontos em comum já se manifestam nos respectivos títulos: "Literatura e subdesenvolvimento", de Antonio Candido, escrito em 1970, publicado então em francês, e republicado em português, na revista Argumento, em 1973, no mesmo número 1 em que saiu o segundo texto, "Cinema: trajetória no subdesenvolvimento", de Paulo Emílio Salles Gomes, editado postumamente em livro de mesmo título ${ }^{3}$.

No caso de Antonio Candido, valho-me também do ensaio "Literatura de dois gumes", publicado pela primeira vez em 1968. De Paulo Emílio, tomo ainda os seguintes textos: "Pequeno cinema antigo" e "Panorama do cinema brasileiro (1896/1966)", ambos publicados no mesmo livro supracitado.

3 GOMES, Paulo Emílio Salles. Cinema: trajetória no subdesenvolvimento. Rio de Janeiro: Paz e Terra e Embrafilme, 1980.

4. A edição citada é CANDIDO, Antonio. A educação pela noite e outros ensaios. São Paulo: Ática, 1989. p. 140-162. 
No processo de produção da antologia de Antonio Candido em alemão ${ }^{5}$, escrevi, com o tradutor Marcel Vejmelka, uma introdução que, antes de publicar, submeti à leitura crítica de Antonio Candido. Em correspondência subsequente e em uma conversa telefônica, ele criticou amavelmente $o$ fato de o classificarmos como um pensador, argumentando com sua proverbial modéstia: "Creio que não posso ser qualificado como pensador, pois não tenho perfil filosófico, além de não ter um conjunto de ideias originais. Eu ficaria mais à vontade se me qualificasse como o que de fato sou: crítico literário"

Essa modéstia, aliás, é própria da sua geração, a "geração clima" e, em outras ocasiões, ele mesmo a comenta, quando se refere a Paulo Emílio Salles Gomes. Mas, ao fazê-lo, se contradiz, reconhecendo nesse um pensador, embora não no sentido filosófico clássico. Dele diz Antonio Candido, na orelha do livro acima mencionado:

Os estudos deste livro mostram até que ponto o seu pensamento era original e penetrante. Nada de propriamente filosófico, mesmo porque a abstração sistemática e a posição científica não o atraíam, como não atraíam o nosso grupo. O que ele tinha era a maestria singular de dizer o necessário através de tiradas e imagens certeiras, nascidas da experiência das artes, da literatura, e de uma curiosidade apaixonada pelas coisas da vida. Da aparente diluição de propósitos extraía a maneira de captar o essencial; e isto faz de seus escritos uma verdadeira iluminação. ${ }^{7}$

A verdade é que ambos são, a seu modo, ou de um modo muito latino-americano, pensadores, que concebem a sociedade brasileira e a vida humana através dela, a partir das obras da cultura, no caso de Antonio Candido, especialmente a literatura e, de Paulo Emílio, o cinema. Os dois o fazem utilizando o ensaio, em que é visível o movimento dialético, que busca desvendar a especificidade, os avanços, recuos e impasses, mas também as possibilidades da cultura colonial e neo ou pós-colonial, procurando tratar, ao mesmo tempo, das duas pontas do mesmo nó: a da produção e a da difusão.

Pelo lado da produção das obras da cultura e da literatura, pode-se dizer que há muito tempo não se pode mais falar em centro e periferia,

5 CHIAPPINI, Ligia (Org.). Literatur und Gesellschaft Antonio Candido. Trad. de Marcel Vejmelka. Frankfurt am Main: Vervuert, 2005.

6 Telefonema realizado em 14/06/2004.

7 GOMES, Paulo Emílio Salles. op. cit. Trecho da segunda orelha, escrita por Antonio Candido. 
dicotomicamente encarados. Os grandes analistas dessa produção sempre mostraram que ela é, simultaneamente, regional, nacional e global, ou, pelo menos, ocidental. Mas, do lado da recepção e das instituições que definem os campos (editoras e Universidades, entre outras), há centro e periferia sim. Uma prova, entre outras, é a eterna luta pela manutenção dos cursos de português na Europa, sempre ameaçados de extinção. Apesar das marcas inegáveis da interdependência cultural no mundo cada vez mais globalizado, onde os agentes literários têm um papel determinante, a literatura brasileira continua periférica, pelo menos em alguns aspectos, tendo em vista assimetrias de todo tipo. Algumas delas se fazem muito presentes atualmente na Alemanha, onde, além da grande restrição que sofre o seu estudo, e pour cause, os maiores escritores brasileiros continuam sendo desconhecidos, ou conhecidos apenas pelo círculo meio exótico de alguns poucos "brasilianistas"8.

\section{Literatura no subdesenvolvimento ou condição periférica: o nó}

Paulo Emílio fala do Brasil como um país de "ocupantes e ocupados"9. Antonio Candido, ao referir-se à América Latina, usa a expressão "continente sob intervenção"10. Para ambos, reconhecer a situação periférica é a primeira condição para superá-la, aproveitando as brechas que existem para a criação de um modo original de ser dependente. Isso implica vencer a passividade da mera imitação do alheio, que, na ânsia de ser cosmopolita ou universal a qualquer custo, muitos escritores e cineastas adotam, sem levar em conta as condições locais e o público imediato.

No ensaio significativamente intitulado "Literatura de dois gumes" Antonio Candido explicita essa condição contraditoriamente dependente nestes termos:

[...] na sua formação, as nossas literaturas são essencialmente européias, na medida em que continuam a pesquisa da alma e da sociedade definida na tradição das metrópoles. Tanto mais

8 A Alemanha, depois de ter ousado abrir, e manter por quinze anos, um cargo de titular de Literatura e cultura Brasileiras (Brasilianistik), único no gênero em todo o país, senão em toda Europa, em 2010 voltou à situação anterior, concentrando novamente a pesquisa e o ensino dessa área, já em si ampla e diversificada, no enorme campo das literaturas e culturas latino-americanas, que inclui, além de toda Hispanoamérica e o Brasil, também o Caribe e a chamada cultura chicana, dos Estados Unidos.

9 GOMES, Paulo Emílio Salles. op. cit., p. 77 .

10 CANDIDO, Antonio. Literatura e subdesenvolvimento. Argumento, n. 1, 1973. p. 146. 
quando foram transpostas à América na era do Humanismo, isto é, quando o homem europeu intensificava o seu contato com as fontes greco-latinas e manifestava grande receptividade em relação a outras formas de cultura, das quais ia tendo a revelação. De maneira que herdamos relativamente pouco do que havia de popular, mágico-religioso e espontâneo na literatura da Idade Média; e muito, ao contrário, de uma literatura erudita, cheia de exigências formais, aberta para uma visão realista e, ao mesmo tempo, alegórica da vida.

Mas, de outro lado, este tipo de literatura veio atuar em regiões desconhecidas, habitadas por povos de cor e tradição diferentes [...] aos quais se juntaram logo outros povos trazidos da África, aumentando a complexidade do panorama. Em conseqüência, a literatura foi obrigada a imprimir na expressão herdada certas inflexões que a tornaram capaz de exprimir também a nova realidade natural e humana. Deste modo, deu-se no seio da cultura européia uma espécie de experimentação, cujo resultado foram as literaturas nacionais da América Latina no que têm de prolongamento e novidade, cópia e invenção, automatismo e espontaneidade. E elas foram se tornando variantes de tal modo diferenciadas das literaturas matrizes que, já nos últimos cem anos, chegaram nalguns casos a influir nelas. ${ }^{11}$

Todo esse ensaio se arma com exemplos do século XVIII, sobretudo para mostrar os dois gumes. Isto é, se, de um lado, a literatura brasileira é "peça eficiente do processo colonizador", por outro, ela vai ser "contraveneno". Historiando a formação da literatura brasileira, que se faz junto com a formação da nação, Antonio Candido mostra como a colonização portuguesa foi criando sua própria contradição, na medida em que se modificava para se adaptar, e ao consolidar as classes dominantes da Colônia. $^{12}$

Assim, a possibilidade de ajustar a tradição ao meio, trazia em si, ao lado da disciplina, uma considerável liberdade; e da combinação de ambas formou-se a expressão ao mesmo tempo geral e

11 CANDIDO, Antonio. Literatura de dois gumes. In: . A educação pela noite e outros ensaios. op. cit., p. 164-165.

12 Idem, ibidem, p. 167. 
particular, universal e local, que a literatura do tempo da Colônia transmitiu como conquista sua. ${ }^{13}$

O que o ensaio tenta descrever é um duplo processo de integração e diferenciação, de incorporação do geral, de mentalidade e normas da Europa para obter a expressão particular, inventariando "aspectos novos que iam surgindo no processo de amadurecimento do País"14.

De modo similar, Paulo Emílio traça um panorama do cinema brasileiro no seu intento de escapar ao subdesenvolvimento, caindo sempre nele, mas também escapando parcialmente, numa luta incessante.

Em ambos, portanto, o problema da dependência cultural é enfocado a partir de uma reflexão mais ampla sobre o subdesenvolvimento. Como isso é feito, trataremos a seguir com mais detalhe, ilustrando com algumas citações verdadeiramente antológicas.

\section{Literatura e subdesenvolvimento: sim e não}

Em "Literatura e subdesenvolvimento", Antonio Candido parte da ideia de país subdesenvolvido contrapondo-a à antiga ideia de país novo e estabelecendo uma cronologia. Antes de 1920, o país seria visto como novo e a sua literatura seria portadora da visão pitoresca, grandiosa, grandiloquente, compensando o atraso pela grandeza da natureza e uma esperança divina, como a que se expressa no hino nacional brasileiro, cuja letra descreve um Brasil gigante e um povo esperançoso. Em 1930, já apareceria uma pré-consciência do subdesenvolvimento, perceptível no romance regionalista de denúncia e análise social. E, a partir de 1950, com Guimarães Rosa, isso se agudizaria numa consciência plena desse subdesenvolvimento.

A mudança de perspectiva evidenciaria "a realidade dos solos pobres, das técnicas arcaicas, da miséria pasmosa das populações, da sua incultura paralisante"15. E tal visão seria "pessimista quanto ao presente e problemática quanto ao futuro"16. A Literatura, tradicionalmente empenhada no Brasil, ganharia então um novo empenho, sendo a consciência do subdesenvolvimento uma "força propulsora"17. A primeira

13 Idem, ibidem, p. 178.

14. Idem, ibidem, p. 179 .

15 CANDIDO, Antonio. Literatura e subdesenvolvimento. op. cit., p. 14,2.

16 Idem, ibidem, p. $14,2$.

17 Idem, ibidem, p. 142 . 
atitude teria sido de "amenidade e curiosidade"; a segunda, desmistificadora, principalmente no romance que "precede a tomada de consciência dos economistas e políticos"18.

Quanto às condições de difusão, faz parte delas o analfabetismo, ligado ao que Antonio Candido chama de "debilidade cultural" por falta de meios de comunicação e difusão (editoras, bibliotecas, revistas, jornais); a inexistência ou dispersão e pequeno número de leitores reais (muito menor que o número já reduzido de alfabetizados); a impossibilidade de especialização dos escritores em suas tarefas literárias, geralmente realizadas como atividades marginais ou mesmo amadorísticas; a falta de resistência ou discriminação em face de influências e pressões externas; "mais alguns fatores de debilidade econômica e política", como a "anarquia financeira dos governos”, os "níveis insuficientes de remuneração", as "políticas educacionais ineptas ou criminosamente desinteressadas"19. Fatores que, alerta, não se combinam mecanicamente, mas de modo distinto em diferentes momentos e países, sendo possível distinguir uma difusão normal de outra, anormal:

É normal, por exemplo, que a imagem do herói de far-west se difunda, porque, independente dos juízos de valor, é um dos traços da cultura norte-americana, incorporado à sensibilidade média do mundo contemporâneo. [...] Mas é anormal que tais imagens sirvam de veículo para inculcar nos públicos dos países subdesenvolvidos atitudes e idéias que os identifiquem aos interesses políticos e econômicos dos países onde foram elaboradas. ${ }^{20}$

Passando ao polo da produção, Antonio Candido pensa a repercussão dessa debilidade cultural e da redução do público na consciência e no trabalho do escritor. $\mathrm{O}$ analfabetismo fazendo com que o escritor queira falar para outros leitores cultos como ele, ou como ele se julga, sendo vítima da ilusão ilustrada da pátria da liberdade como pátria do livro. $\mathrm{O}$ escritor do país subdesenvolvido escreveria, então, para outros leitores de outras pátrias, ou quereria fazer parte de um grupo à parte, flutuante:

Flutuavam, com ou sem consciência de culpa, acima da incultura e do atraso, certos de que estes não os poderiam contaminar, nem afetar a qualidade do que faziam. Como o ambiente não os podia

18 Idem, ibidem, p. 142.

19 Idem, ibidem, p. 143.

20 Idem, ibidem, p. 145. 
acolher intelectualmente senão em proporções reduzidas, e como os seus valores radicavam na Europa, para lá se projetavam, tomando-a inconscientemente como ponto de referência e escala de valores; e considerando-se equivalentes ao que havia lá de melhor. ${ }^{21}$

Mas, dialeticamente, esse fenômeno é analisado como tendo consequências negativas e também positivas. O lado negativo, de "bazar de afetação" ou "joias falsas", dever-se-ia a que "a incultura geral produzia e produz uma debilidade ainda mais penetrante, que interfere em toda a cultura e na própria qualidade das obras"22. O lado positivo estaria num movimento pendular das elites, já estudado longamente no livro Formação da literatura brasileira, entre a realidade e a utopia de cunho ideológico: "as elites imitavam, por um lado, o bom e o mau das sugestões europeias; mas, por outro, às vezes simultaneamente, afirmavam a mais intransigente independência espiritual, num movimento pendular"23.

Nesse caso, o que se impõe é a exigência do peso da realidade local, pois quando, por exemplo, na Europa, o Naturalismo já estava ultrapassado e mal sobrevivia, no Brasil revelava-se "ingrediente de fórmulas literárias legítimas", sobretudo no romance de cunho social das décadas de 1930 e $1940^{24}$.

Antonio Candido, como mostrou Sandra Nitrini ${ }^{25}$, inova na visão da cópia e da influência, ao distinguir a influência inevitável, sociologicamente vinculada à nossa dependência desde a colonização, de um lado, e, o transplante cultural grosseiramente forçado, de outro. Ser contrário à admiração cega, entretanto, é possível, mas sem jogar fora a criança com a água do banho. Por isso, o crítico reconhece que seria pueril negar, por exemplo, a influência da poesia ou da ciência francesas, para ser independente a qualquer custo, e propõe seguir o bom-senso de tomar os empréstimos com discernimento e prudência.

Na sua visão, o "vínculo placentário com as literaturas européias" não é uma opção, mas um "fato quase natural". Prova disso seria que nem os nativismos criaram quadros originais de expressão. Resultados originais seriam muito mais os usos adaptados de formas importadas. E estaria aí o que ele denomina "processo de fecundação criadora da dependência - modo peculiar de os nossos países serem

21 Idem, ibidem, p. $14,8$.

22 Idem, ibidem, p. $14,8$.

23 Idem, ibidem, p. 149.

24. Idem, ibidem, p. 150 .

25 NITRINI, Sandra. Introdução à literatura comparada. São Paulo: Edusp, 1997. 
originais"26, o que, veremos, Paulo Emílio denominaria criativamente de: "incompetência criativa em copiar"27.

O ensaio de Candido termina com uma exemplar análise do fenômeno do regionalismo e sua pertinência em regiões subdesenvolvidas, também se desenvolvendo, da visão eufórica à “consciência dilacerada do subdesenvolvimento", como no caso de Guimarães Rosa, que superaria desde dentro o que "foi um dia o nativismo" 28 .

\section{Cinema e subdesenvolvimento: a danação periférica no presente no passado e no futuro?}

Em textos anteriores ao "Cinema: trajetória no subdesenvolvimento", reunidos na coletânea já citada, Paulo Emílio historiava brevemente a formação e o desenvolvimento do cinema brasileiro, alertando para que o fato de "a novidade cinematográfica chegou cedo ao Brasil" "29, com os primeiros aparelhos entrando no país um ou dois anos depois das exibições europeias e norte-americanas. Depois das primeiras exibições brasileiras, em 1898, teria ocorrido um atraso, principalmente por insuficiência de energia elétrica, o que só em 1907 teria sido resolvido, com a energia elétrica produzida industrialmente no Rio de Janeiro. A partir daí, a abertura de várias salas, primeiramente na então capital do país e, logo depois, em São Paulo, teria agilizado a importação de filmes estrangeiros e, em pouco tempo, a produção do cinema nacional. E entre 1908 e 1911 o Rio teria conhecido "a idade de ouro do cinema brasileiro" ${ }^{30}$, embora logo travada pela impossibilidade de um país periférico acompanhar o desenvolvimento industrial da nova arte:

Essa idade de ouro não podia durar, pois sua eclosão coincide com a transformação do cinema artesanal em importante indústria nos países mais adiantados. Em troca do café, que exportava, o Brasil importava até palito e era normal que importasse também o entretenimento fabricado nos grandes centros da Europa e da América do Norte. Em alguns meses o cinema nacional eclipsou-se

26 CANDIDO, Antonio. Literatura e subdesenvolvimento. op. cit., p. 161.

27 GOMES, Paulo Emílio Salles. op. cit., p. 77.

28 CANDIDO, Antonio. Literatura e subdesenvolvimento. op. cit., p. 162.

29 GOMES, Paulo Emílio Salles. op. cit., p. zo.

zo Idem, ibidem, p. 31 . 
e o mercado cinematográfico brasileiro, em constante desenvolvimento, ficou inteiramente à disposição do cinema estrangeiro. ${ }^{31}$

A partir de 1925, teria havido um novo surto de filmes nacionais, quantitativa e qualitativamente significativo, porém novamente interrompido, com a chegada do cinema falado. E uma nova crise teria gerado, nos termos de Paulo Emílio, "um longo e penoso reinício"32.

Faz parte desse reinício a descoberta e propagação de um novo gênero - a chanchada -, sobre a qual a afirmação de Paulo Emílio, destacada abaixo, é tão esclarecedora e instigante, que abriu espaço para outros estudos pioneiros, como foi o caso das pesquisas e dos escritos de Jean Claude Bernardet sobre o tema alguns anos depois. Diz ela:

O resultado mais evidente foi a proliferação de um gênero de filmes - a comédia popularesca, vulgar e freqüentemente musical - que desolou mais de uma geração de críticos. Uma visão mais aguda permitiria vislumbrar, nessas fitas, destinadas aos setores mais modestos da sociedade brasileira, algumas virtualidades que mereceriam estudo e desenvolvimento. Durante vinte anos esse gênero - que só decaiu no cinema quando foi absorvido pela televisão - registrou e exprimiu aspectos e aspirações do panorama humano do Rio de Janeiro. ${ }^{33}$

O ensaio prossegue, passando pelo esforço cosmopolita semi-malogrado da Cia. Cinematográfica Vera Cruz, nos anos 1950, em São Paulo, para chegar ao alvorecer do cinema novo, no final dessa década, o que não teria impedido a persistência dos "arrivistas de espírito" ${ }^{34}$ ou daqueles que, quase simultaneamente, Antonio Candido chamaria de "provincianos-cosmopolitas".

No final do panorama que faz do cinema brasileiro, o crítico conclui que o único momento em que difusão e produção se teriam encontrado e complementado teria sido por volta dos anos 1910, quando os donos das

31 Idem, ibidem, p. 31.

$3^{2}$ Idem, ibidem, p. $3^{2}$.

33 Idem, ibidem, p. $3^{2}$.

34. Os arrivistas de espírito desejam atingir verdades universais e permanentes do ser humano acima de qualquer conjuntura social definida. [...] Durante algum tempo, o empenho maior do grupo foi reagir passionalmente contra o cinema do após guerra, notadamente o italiano que dignificava uma humanidade que lhes era biograficamente próxima, mas à qual desesperavam em dar as costas. Seus filmes revelam no melhor dos casos um talento de feitura perdido na indigência dos argumentos e roteiros. Idem, ibidem, p. 33-34. 
salas de cinema eram os mesmos que produziam e importavam. Mas isso se teria perdido, instaurando-se apenas a ilusão de que a indústria cinematográfica estaria funcionando normalmente no Brasil.

Tal não acontece. Os interesses do comércio cinematográfico nacional giram em torno do cinema importado, prosseguindo o mercado atual saturado pelo produto estrangeiro. São obrigados os nossos filmes a enfrentar o desinteresse e conseqüente má vontade do comércio, conseguindo exibição graças apenas ao amparo legal. ${ }^{35}$

Finalmente, essa conjuntura da difusão se refletiria na produção e a limitaria ou artificializaria:

Uma das conseqüências dessa situação injusta é levar produtores e cineastas a se preocuparem demasiadamente com a exportação dos respectivos filmes, superestimando a importância dos festivais internacionais. As inteligências e energias ficam assim distraídas do único objetivo que realmente importa ao nosso filme: o público e o mercado brasileiro. O problema não é aumentar o número de filmes a serem apresentados no exterior, mas sim diminuir o número de fitas estrangeiras aqui exibidas. Será preciso reconquistar, em modernos termos industriais, a harmoniosa situação que existiu no Brasil de 1910: a de solidariedade de interesses entre os donos das salas de cinema e os fabricantes de filmes nacionais. ${ }^{36}$

Em “Cinema: trajetória no subdesenvolvimento", essas reflexões se sistematizam na comparação com o cinema mundial, mostrando que o cinema brasileiro, hindu e árabe jamais deixaram a condição de subdesenvolvidos, ao contrário do norte-americano, do japonês e do europeu, que nunca teriam experimentado o subdesenvolvimento. Mas o caso brasileiro teria ainda uma peculiaridade a ser levada em conta na comparação:

A situação cinematográfica brasileira não possui um terreno de cultura diverso do ocidental, onde possa deitar raízes. Somos um prolongamento do ocidente, não há entre eles e nós

35 Idem, ibidem, p. 69 .

$3^{6}$ Idem, ibidem, p. 7 o. 
a barreira natural de uma personalidade hindu ou árabe, que precise ser conscientemente sufocada, contornada e violada. ${ }^{37}$

$\mathrm{E}$, nesse momento, o texto chega a uma dessas formulações antológicas que permanecem anos na nossa memória, porque iluminam original e ironicamente um problema complexo:

Nunca fomos propriamente ocupados. Quando o ocupante chegou o ocupado existente não lhe pareceu adequado e foi necessário criar outro. A importação maciça de reprodutores, seguida de cruzamento variado, assegurou o êxito na criação do ocupado, apesar da incompetência do ocupante agravar as adversidades naturais. A peculiaridade do processo, o fato do ocupante ter criado o ocupado aproximadamente à sua imagem e semelhança, fez deste último, até certo ponto o seu semelhante. Psicologicamente, ocupado e ocupante não se sentem como tais: de fato, o segundo também é nosso e seria sociologicamente absurdo imaginar a sua expulsão, como os franceses foram expulsos da Argélia. Nossos acontecimentos históricos - independência, república, revolução de trinta - são querelas de ocupantes nas quais o ocupado não tem vez. O quadro se complica quando lembramos que a metrópole do nosso ocupante nunca se encontra onde ela está, mas em Lisboa, Madri, Londres ou Washington. [...]

Não somos europeus nem americanos do norte, mas destituídos de cultura original, nada nos é estrangeiro, pois tudo o é. A penosa construção de nós mesmos se desenvolve na dialética rarefeita entre o não ser e o ser outro. O filme brasileiro participa do mecanismo e o altera através de nossa incompetência criativa em copiar. ${ }^{38}$

É essa perspectiva que permite a Paulo Emílio, contra o gosto dominante da crítica, valorizar a chanchada dos anos 1940, como um marco importante do cinema brasileiro, e o seu sucesso junto a um público "plebeu e juvenil", ao longo de "vinte anos de produção ininterrupta, desvinculada do gosto do ocupante e contrária ao interesse estrangeiro" 39. Segundo ele, as obras do gênero traziam "marcas do mais cruel subdesenvolvimento; contudo, o acordo que se estabelecia entre elas e o espectador era um fato cultural incomparavelmente mais vivo

37 Idem, ibidem, p. 77 .

38 Idem, ibidem, p. 77 .

39 Idem, ibidem, p. 79-8o. 
do que o produzido até então pelo contato entre o brasileiro e o produto cultural norte-americano" ${ }^{40}$. A diferença teria consistido em passar de uma "passividade consumidora" a uma participação "com elementos de criatividade" $"$.

O sucesso da chanchada teria motivado as elites paulistas a criar um cinema nacional de qualidade. Mas estas teriam tido a ilusão sobre a disponibilidade das salas de exibição para qualquer tipo de filme e sobre a possibilidade de conquistar um público mais culto. Tais ilusões teriam levado esse projeto ao fracasso. Em contrapartida, na visão sempre otimista de Paulo Emílio, acostumado a indagar sobre as vantagens do atraso, o fracasso teria atraído a atenção de todos para a fragilidade do cinema brasileiro, que passou a cobrar medidas de amparo do governo, embora isso também se configurasse como ilusão, agora de caráter político, pois uma nova política cinematográfica não teria sido capaz de alterar as limitações impostas pelo mercado, que continuaria "ocupado pelo estrangeiro, a cujos interesses serviria prioritária e diretamente o comércio cinematográfico no Brasil”42.

Com respeito ao Cinema Novo, Paulo Emílio reconhece a forma original como este aproveitou o melhor do neorrealismo, mas constata que ele tampouco conseguiu romper esse círculo vicioso. Feito por uma classe média para uma classe média ou média alta, tal cinema teria instaurado uma homogeneidade social entre os produtores e o público, sem atingir mais amplamente os espectadores das camadas populares, como ocorreu com a chanchada. Entretanto, apesar desse limite claro, o Cinema Novo teria sido muito importante, sobretudo porque teria criado "uma imagem visual e sonora, contínua e coerente, da maioria absoluta do povo brasileiro, disseminada nas reservas e quilombos", embora, ignorasse a fronteira entre os 30\% dos “ocupados", que constituíam seus expectadores, e os 70\% deles, que não conseguia alcançar ${ }^{43}$.

As últimas expressões do cinema nacional de que Paulo Emílio trata nesse texto são os chamados "cinema do lixo" $\mathrm{e}$ "cinema comercial". Em ambos ele vê pontos negativos e positivos, mesmo no que instauraria "a circulação da tolice", pois, "de qualquer maneira e apesar de tudo", iam essas fitas "cumprindo bem a missão de tentar substituir o produto estrangeiro" $"$.

40 Idem, ibidem, p. 8 .

4.1 Idem, ibidem, p. 8 o.

4,2 Idem, ibidem, p. 81.

43 Idem, ibidem, p. 83-84.

44. Idem, ibidem, p. 84. 
No final, o cinema nacional apresentaria um leque mais variado da produção para o mercado e enfrentaria a complexidade de produzir para um público não identificado. Mas ainda restaria um certo mal-estar: voltado para o estrangeiro, encontra uma compensação falaciosa, em que a diversão impediria de assumir a frustração, primeiro passo para superá-la ${ }^{45}$.

Falando ainda da deserção do cinema pelo público brasileiro de uma elite intelectual, o crítico resume novamente o problema de modo preciso:

Rejeitando uma mediocridade com a qual possui vínculos profundos, em favor de uma qualidade importada das metrópoles com as quais tem pouco o que ver, esse público exala uma passividade que é a própria negação da independência a que aspira. Dar as costas ao cinema brasileiro é uma forma de cansaço diante da problemática do ocupado e indica um dos caminhos de reinstalação da ótica do ocupante. ${ }^{46}$

Sair da passividade para esse público e, consequentemente, para o cinema brasileiro requereria "reanimação sem milagre da vida brasileira". Paulo Emílio não deixava de acreditar na possibilidade de uma nova cultura brasileira nascida desse processo. $\mathrm{O}$ texto acaba quase que profeticamente, parecendo acreditar que o círculo vicioso do subdesenvolvimento, no caso do cinema, só poderia ser rompido por saídas de outra ordem, social e econômica ${ }^{47}$. Paulo Emílio não fala diretamente de interdependência, palavra tão em voga hoje em dia. Para ele, como para Antonio Candido, mas para o primeiro de forma que parece ainda mais inevitável, trata-se de uma fatal dependência:

A esterilidade do conforto intelectual e artístico que o filme estrangeiro prodiga faz da parcela de público que nos interessa uma aristocracia do nada, uma entidade em suma muito mais subdesenvolvida do que o cinema brasileiro que desertou. Não há nada a fazer a não ser constatar. ${ }^{48}$

45 Idem, ibidem, p. 87.

46 GOMES, Paulo Emílio Salles. Pequeno cinema antigo. op. cit., p. 87 .

47 Haveria aqui toda uma discussão a fazer, hoje, quando o país está bem diferente nessas duas ordens, mas os cineastas e artistas em geral se juntam ainda prioritariamente para pedir novas medidas protecionistas ao Ministério da Cultura.

48 GOMES, Paulo Emílio Salles. op. cit., p. 87. 
Já para Antonio Candido, a dependência teria, como tudo, seus avessos, daí a sua afirmação, que me parece de grande atualidade para quem pretende ir além da dicotomia entre centro e periferia num mundo interdependente e globalizado:

[...] vista assim (a dependência), ela deixa de o ser, para tornar-se forma de participação e contribuição a um universo cultural a que pertencemos que transborda as nações e os continentes, permitindo a reversibilidade das experiências e a circulação dos valores. Mesmo porque, nos momentos em que influímos de volta nos europeus, no plano das obras realizadas por nós (não no das sugestões temáticas que o nosso continente oferece para eles elaborarem como formas mais ou menos acentuadas de exotismo), em tais momentos o que devolvemos não foram invenções mas um afinamento dos instrumentos recebidos. ${ }^{49}$

O que seria preciso entender, sobretudo nos dias atuais, e que não é nada simples, porque também aí somos passíveis de muitas ilusões, é o que Candido chama de "fidelidade local" no contexto de uma "mobilidade mundial" 50 . O que implica a necessidade de vencer o receio, "que leva à aceitação indiscriminada ou à ilusão de originalidade por obra e graça do temário local" ${ }^{51}$.

Antonio Candido dá dois exemplos na literatura latino-americana, que seriam expressivos do que ele chama "universalismo da região": João Guimarães Rosa e Juan Rulfo ${ }^{52}$. Talvez no cinema tudo isso seja mais complicado. Se o é pelo fato de depender muito mais do progresso técnico e por enfrentar monopólios muito mais poderosos no comércio e na indústria cinematográficos, não dá para esquecer o empecilho que representa, no caso da literatura, além da globalização agressiva das grandes editoras, uma língua não hegemônica como o português. $O$ exemplo de Borges e Machado, e a dificuldade maior na difusão deste último pelas barreiras da língua, tampouco escapam à análise perspicaz de Antonio Candido:

[...] é possível dizer que Jorge Luís Borges representa o primeiro caso de incontestável influência original, exercida de maneira

49 CANDIDO, Antonio. Literatura e subdesenvolvimento. op. cit., p. 152.

5o Idem, ibidem, p. 156.

51 Idem, ibidem, p. 156 .

$5^{2}$ Idem, ibidem, p. 162. 
ampla e reconhecida sobre os países-fontes, através de um modo novo de conceber a escrita. Machado de Assis, cuja originalidade não é menor sob este aspecto, e muito maior como visão do homem, poderia ter aberto rumos novos no fim do século XIX para os países-fontes. Mas perdeu-se na areia de uma língua desconhecida num país então completamente sem importância. ${ }^{53}$

O nó a ser desatado, como vimos no resumo do debate com que iniciamos este texto, requer ainda hoje uma terceira via, que consiste em superar a mera "passagem aristocrática da era das oligarquias, para a manipulação dirigida das massas, na era da propaganda e do imperialismo total" ${ }^{54}$. Sem fórmulas mágicas, podemos encerrar, sustentando que desatar o nó passa por retomar, junto com a sempre bem-vinda importação de modelos do primeiro mundo, a tradição construída a duras penas no país - como o cinema de jovens cineastas vem fazendo com muito do cinema atual; como Machado fez com Alencar; como Drummond com o Modernismo; Cabral com Drummond; e Antonio Candido com Sílvio Romero, entre outros. Só assim poderemos nos precaver contra propostas descosidas que repetem os limites do passado.

Essa terceira via poderia ser assim resumida: nem o ressentimento patético e isolacionista nem a infantil rebeldia negadora desses limites. No caso da literatura, ser grande em sua língua e ser bem traduzido para ser lido em outras línguas e lugares. E não tentar o caminho inverso de alguns escritores apressados, que, com ajuda de alguns agentes literários igualmente sem tempo, sem paciência e sem rigor, querem ter seus textos lidos além-fronteiras, sem cuidar se estão mal escritos na sua ou nas outras línguas. Nesse caso, para chegar à interdependência, para além das ilusões frágeis, é ainda necessária a mediação da velha crítica, que não abre mão dessas qualidades indispensáveis e cada vez mais raras: rigor e paciência.

53 Idem, ibidem, p. 153.

54 Idem, ibidem, p. 146. 